\title{
Co-agglutination (Co-A) test for circulating antigen in hydatid disease
}

\author{
M. SHARIFF and S. C. PARIJA* \\ Department of Paediatrics, AlIMS, New Delhi-110 029 and *Department of Microbiology, Jawaharlal Institute of \\ Postgraduate Medical Education and Research, Pondicherry-605006, India
}

\begin{abstract}
Summary. A co-agglutination (Co-A) test with Staphylococcus aureus (Cowan's strain I) bearing protein A coated with specific hydatid antibodies, was used to demonstrate circulating hydatid antigen in serum for the diagnosis of hydatid disease. The test had a sensitivity of $95 \%$ and a specificity of $89 \%$ in detecting hydatid antigen in serum. A false positive reaction was observed with $18.5 \%$ of control sera from patients with various parasitic diseases. However, these all gave negative results when tested after further dilution. The test is reliable and rapid; the result could be obtained within $30-45$ min of receipt of a serum sample. Since the test is simple and the reagents are inexpensive and easily available, it can be used in less well equipped laboratories in developing countries.
\end{abstract}

\section{Introduction}

Hydatid disease caused by Echinococcus granulosus is a zoonotic infection of cosmopolitan distribution. Many factors, attributable to the host, the environment and the agent, account for the different patterns of distribution and transmission of infection in different areas. Hydatid disease is being reported increasingly from India. ${ }^{1}$

The manifestations of hydatid disease in man are variable, its clinical diagnosis is complex, and its specific diagnosis is based mainly on immunological tests. Many immunodiagnostic tests have been used in the serodiagnosis of hydatid disease,${ }^{2}$ almost all of which are based on the demonstration of circulating antibodies to E. granulosus in serum. However, an increasing number of false negative results in surgically confirmed cases of hydatid disease is an inherent disadvantage of these tests. Attempts have, therefore, been made recently to devise tests which detect circulating antigen. These tests can also be used for post-treatment evaluation and to quantify the load of the parasite in the patient. $^{3}$ The enzyme-linked immunosorbent assay (ELISA) and its modifications are the only immunoassays available at present to detect circulating antigens in the serum of patients with hydatid disease. ${ }^{4}$ However, ELISA can be performed only in well equipped laboratories. In developing countries, there is a need for equally sensitive and specific, but simpler, immunoassays that can be used in less well equipped laboratories.

We report here the development and evaluation of a bacterial co-agglutination (Co-A) test, for the de- tection of circulating hydatid antigen in serum. The Co-A test was originally developed by Kronvall et al. ${ }^{5}$ for typing pneumococci. In the present context, it is based on the principle that antibodies to E. granulosus that are bound to staphylococcal protein A will react specifically with circulating hydatid antigen in the serum and result in visible clumping of the staphylococcal cells. Protein A binds predominantly to the Fc portion of IgG without affecting the antigenbinding capacity of the bound IgG.

\section{Materials and methods}

\section{Sera}

Test sera were collected from patients with hydatid disease, and control sera from patients with other diseases and from healthy staff of the Jawaharlal Institute of Postgraduate Medical Education and Research (JIPMER) Hospital, Pondicherry, India. The groups consisted of: surgically confirmed hydatid disease (SC), 18 cases, 17 of which were tested by CoA; ultrasonographically proven hydatid disease (USP), three cases (this group included cases of unoperated hydatid disease, diagnosed by radiography and ultrasonography); presumptive hydatid disease (PHD), 26 cases (this group included patients who were admitted with a clinical diagnosis of hydatid disease that was not confirmed by other methods); hydatid disease controls (CP), 26 cases (this group included 22 cases of other parasitic infections-10 cases of amoebiasis, 10 of filariasis, one of falciparum malaria, one of hookworm infection-and four cases of malignant disease); healthy controls $(\mathrm{CH}), 23$ cases 
(this group consisted of healthy adults - staff, students and blood donors - who had not suffered from hydatid disease in the recent past).

The sera were stored at $-20^{\circ} \mathrm{C}$ until used.

\section{Antigen}

Antigen was prepared from human hydatid cyst fluid (HHCF) collected from hepatic, mesenteric and abdominal cysts at operation and processed according to the method described previously. ${ }^{6}$ Hydatid fluid was aspirated aseptically and checked for the presence of scolices and hooklets. The fluid was filtered with a Seitz asbestos filter and was checked for possible bacterial contamination by the usual microbiological methods. The protein content was estimated by Lowry's method. ${ }^{7}$ The antigen was divided into portions and stored at $-20^{\circ} \mathrm{C}$ until used.

\section{Hyperimmune antiserum}

Adult rabbits weighing 3-4 kg were inoculated intramuscularly with $1 \mathrm{ml}$ of human hydatid cyst fluid (protein $0.5 \mathrm{mg} / \mathrm{ml}$ ) emulsified with an equal volume of Freund's complete adjuvant. After 6 weeks, they were inoculated with the same volume of antigen in Freund's incomplete adjuvant. Serum was collected 10 days later and monitored for antibodies to the HHCF antigen by indirect haemagglutination (IHA).

\section{Staphylococcus aureus (Cowan's strain I) bearing protein $A(S A P A)$}

SAPA cells were grown on Mueller-Hinton agar at $37^{\circ} \mathrm{C}$ and fixed with formalin as described previously. ${ }^{8}$ After incubation for $18 \mathrm{~h}$ with aeration, SAPA cells were harvested and centrifuged at $3000 \mathrm{~g}$ for $10 \mathrm{~min}$ and washed three times in phosphate-buffered saline (PBS), pH 7.2, containing sodium azide $0.05 \%$. The pellet was fixed in 10 volumes of formaldehyde $1.5 \%$ in PBS $(\mathrm{pH} \mathrm{7.2)}$ at room temperature for $90 \mathrm{~min}$, washed three times in the buffer and resuspended in 10 volumes of the buffer containing sodium azide $0.05 \%$, and heated at $80^{\circ} \mathrm{C}$ for $5 \mathrm{~min}$. The cocci were again washed twice and a $10 \%$ suspension in buffer containing sodium azide $0.05 \%$ was then divided into small volumes and stored at $-20^{\circ} \mathrm{C}$.

\section{Co-A test}

Sensitisation of SAPA cells. SAPA cells were sensitised with hyperimmune antiserum immediately after preparation of the cells. Specific hyperimmune hydatid antiserum $(0.1 \mathrm{ml})$ raised in rabbits was added to $1 \mathrm{ml}$ of a $10 \%$ suspension of SAPA cells, mixed thoroughly and incubated at $37^{\circ} \mathrm{C}$ for $30 \mathrm{~min}$. The sensitised SAPA cells were washed once and resuspended to a concentration of $2 \%$ in PBS (pH 7.2) containing sodium azide $0 \cdot 1 \%$. A $2 \%$ suspension of unsensitised cells was used as the control.
Co-agglutination reaction. A glass slide surface was divided with a glass marking pencil into two halves. A drop of test serum was placed on each half of the slide. An equal volume of sensitised SAPA cell suspension was added to the serum on one half. The same volume of a $2 \%$ suspension of unsensitised SAPA cells was added to the serum on the other half as a cell control. The slide was then rotated manually for 2 min and inspected. Agglutination with the sensitised cells and not with the unsensitised cells was considered to be a positive result.

Appropriate controls were examined in parallel with each test. With every batch, sera known to be positive and negative for hydatid were included.

The cell control and negative serum controls in the slides were examined first, and the end-points of the reference positive and test sera were determined.

\section{Evaluation of factors influencing the Co-A test}

$S A P A$ cells. The optimum concentration of $S$. aureus was determined by chess-board titration with SAPA cell concentrations of $1,2,3,4$ and $5 \%$ and known positive and negative hydatid sera. The lowest concentration of SAPA cells that showed maximum co-agglutination was considered to be the optimum concentration of $S$. aureus for that batch of cells.

Sensitivity of the Co-A reagent. The Co-A reagent was stored at room temperature, $4^{\circ} \mathrm{C},-20^{\circ} \mathrm{C}$ and $-70^{\circ} \mathrm{C}$. At weekly intervals a batch of sera containing two or three known positive hydatid sera was titrated with stored $\mathrm{Co}-\mathrm{A}$ reagent to evaluate the activity of the reagent.

\section{IHA test}

An IHA test with double-aldehyde-stabilised chick cells, sensitised with the optimum sensitising dose of hydatid antigen, was performed on the same batch of sera by the procedure described earlier. ${ }^{9}$ The IHA tests were performed before the Co-A tests and in eight cases insufficient serum remained for a subsequent $\mathrm{Co}$ A test.

\section{Antibody and antigen profiles}

An attempt was made to study the circulating hydatid antibody and antigen profiles, before and after surgery of three hydatid disease cases, by the IHA test for antibodies and by the Co-A test for antigens.

\section{Results}

In a positive Co-A test, the addition of sensitised SAPA cells to the test serum resulted in the formation of large visible clumps of bacterial cells within $2 \mathrm{~min}$; in a negative reaction, no visible clumping was observed. Clumping was not demonstrated in the cell control that received only unsensitised SAPA cells. 
Table I. Distribution of immunoreactivity of hydatid disease and control sera in the Co-A test

\begin{tabular}{lccccccccccr}
\hline \multirow{2}{*}{$\begin{array}{l}\text { Subject } \\
\text { group }\end{array}$} & $\begin{array}{c}\text { Number of } \\
\text { cases }\end{array}$ & \multicolumn{8}{c}{$\begin{array}{c}\text { Number of sera that gave a positive } \\
\text { result at a dilution of }\end{array}$} & $\begin{array}{c}\text { Number } \\
\text { negative }\end{array}$ & $\begin{array}{c}\text { Number } \\
\text { positive }\end{array}$ \\
\cline { 3 - 8 } & & 64 & 32 & 16 & 8 & 4 & 2 & Neat & & \\
\hline SC & 17 & 3 & 3 & 4 & 2 & 2 & 0 & 2 & 1 & 16 \\
USP & 3 & 0 & 1 & 2 & 0 & 0 & 0 & 0 & 0 & 3 \\
PHD & 26 & 0 & 0 & 0 & 0 & 1 & 2 & 14 & 9 & 17 \\
CP & 26 & 0 & 0 & 0 & 0 & 0 & 0 & 5 & 21 & 5 \\
CH & 23 & 0 & 0 & 0 & 0 & 0 & 0 & 0 & 23 & 0
\end{tabular}

SC, surgically confirmed; USP, ultrasonographically proved; PHD, presumptive hydatid disease; $\mathrm{CP}$, parasitic controls, $\mathrm{CH}$, healthy controls.

Table II. Evaluation of immunoassays in the diagnosis of hydatid disease

\begin{tabular}{lcc}
\hline & $\begin{array}{c}\text { Number of sera (and cases) that } \\
\text { gave positive results by }\end{array}$ \\
\cline { 2 - 3 } & Co-A test & IHA test \\
\hline SC & $16(17)$ & $11(18)$ \\
USP & $3(3)$ & $2(3)$ \\
PHD & $17(26)$ & $17(30)$ \\
CP & $5(26)$ & $4(27)$ \\
CH & $0(23)$ & $0(25)$ \\
Sensitivity & $95 \%$ & $61.9 \%$ \\
Specificity & $89.8 \%$ & $92 \cdot 3 \%$ \\
Positive predictive value & $79.2 \%$ & $76.4 \%$ \\
& & \\
\hline
\end{tabular}

* See table I for explanation of abbreviations.

Only the sera that showed no agglutination with unsensitised cells were included in the study, to eliminate any false positive reactions due to the presence of anti-staphylococcal antibodies. The optimal concentration of SAPA cells for use in the test was $2 \%$.

The results of the Co-A test on the sera from different groups of hydatid disease patients and controls are summarised in table I.

The hydatid-antibody-sensitised SAPA suspension retained its full reactivity during storage for up to 12 weeks at room temperature, 16 weeks at $4^{\circ} \mathrm{C}$ and for $>5$ months at $-20^{\circ} \mathrm{C}$ and $-70^{\circ} \mathrm{C}$.

\section{Comparison with IHA}

Table II shows a comparison of the sensitivity and specificity of Co-A and IHA in the diagnosis of hydatid disease. The Co-A test demonstrated circulating antigens in the sera of five cases of hydatid cysts of lungs, spleen and the abdomen, which gave negative results in the IHA for circulating antibodies.

\section{Antibody and antigen profiles}

A total of three sera obtained pre-operatively from surgically confirmed cases of hydatid disease gave positive IHA results and showed antibody titres ranging from 2 to 2048 .
The antibody titres in the sera of these three cases collected 5 weeks after removal of the cysts were the same as those in the pre-operative sera. The serum collected from one patient 1 year after removal of a cyst showed a significant decrease in the antibody titre demonstrated by the IHA (from a pre-operative titre of 2048 to a post-operative titre of 32). However, there was a significant decrease in the levels of circulating antigen in the sera collected within 10 days of the removal of the hydatid cysts and no antigen could be demonstrated by the Co-A assay thereafter.

\section{Discussion}

Several parasites, including protozoa, cestodes and nematodes, produce soluble antigens which are released into the host tissues and blood stream. ${ }^{3}$ These circulating antigens have been detected in many human parasitic infections such as amoebiasis, toxoplasmosis, malaria, schistosomiasis and lymphatic filariasis. Circulating antigen had been detected previously in experimental larval cestode infections, e.g., Mesocestoides corti and $E$. multilocularis infection of mice, ${ }^{10,11}$ Taenia pisiformis infection of rabbits and, recently, in human echinococcosis. ${ }^{12,13}$ Development of a sandwich ELISA which is highly sensitive and specific for the detection of circulating hydatid antigen in human cases has been reported. ${ }^{3}$ However, laboratories in developing countries lack the technical expertise, expensive equipment and reagents to perform such sophisticated tests. Therefore, there is still a need for the development of simple, yet reliable, tests for the serodiagnosis of hydatid disease.

In our study, the Co-A test detected circulating antigens in $16(94.1 \%)$ sera from surgically confirmed and three $(100 \%)$ sera from ultrasonically proven cases of hydatid disease. The antigen was detectable in both undiluted sera and in sera at a dilution of up to 64 . The assay demonstrated the circulating antigen in $17(65 \cdot 4 \%)$ clinically suspected cases of hydatid disease. The sensitivity of the assay in the detection of hydatid antigen in this study (table II) compares well with that of ELISA $(85 \%)$ as reported by Craig et $a l .{ }^{14}$ The Co-A test was found to be equally specific 
and no false positive reaction was observed with the sera from healthy controls. Five $(19 \%)$ undiluted sera from control patients with other parasitic diseases showed false positive reactions, but all gave negative results when tested after further dilution.

The Co-A test was more sensitive but less specific than the IHA in the diagnosis of hydatid disease (table II). Of the cases of surgically confirmed hydatid disease, the Co-A test detected five cases in which the IHA test for circulating antibodies gave negative results.

The demonstration of circulating hydatid antigen can play a useful role in the post-treatment monitoring of cases. ${ }^{3.4}$ In this study, paired sera were obtained before and after operation from three patients; the levels of circulating antigen as demonstrated by the Co-A test in the sera of all three cases declined within 3-10 days after removal of the cyst. However, no marked difference in the antibody profiles between the pre- and post-operative sera of surgically confirmed cases of hydatid disease were shown by IHA. Circulating antibody was detectable for more than a year after removal of the cyst.

\section{References}

1. Roy SC, Chakravarthy M, Das MM, Chattergee PP. World incidence of hydatid disease in general and pulmonary hydatid disease in particular with special reference to India. $J$ Indian Med Assoc 1970; 55: 212-217.

2. Parija SC, Rao RS. Enhancement of sensitivity of haemagglutination test for echinococcosis by use of Staphylococcus aureus protein A. J Med Microbiol 1986; 22: $241-244$

3. Gottstein B. An immunoassay for the detection of circulating antigens in human echinococcosis. Am J Trop Med $\mathrm{Hyg}$ 1984; 33: 1185-1191.

4. Craig PS, Nelson GS. The detection of circulating antigen in human hydatid disease. Am Trop Med Parasitol 1984; 78 : 219-227.

5. Kronvall $G$. A rapid slide agglutination method for typing pneumococci by means of specific antibody absorbed to protein A containing staphylococci. J Med Microbiol 1973; 6: $187-190$.

6. Parija SC, Ananthakrishnan N. Evaluation of stabilised cells in the indirect haemagglutination test for echinococcosis. $J$ Med Microbiol 1985; 19: 95-98.

7. Lowry OH, Rosenbrough NJ, Farr AL, Randall RJ. Protein measurement with the folin phenol reagent. $J$ Biol Chem $1951 ; 193: 265$.

8. Parija SC, Mehta RB, Rao RS. A study of use of chick cells in
The findings of this study are encouraging and show that both pre- and post-operative evaluation of circulating hydatid antigen by $\mathrm{Co}-\mathrm{A}$ can be very helpful in monitoring the post-operative course of cases of hydatid disease.

The stability of the Co-A reagent, as observed in this study, is also corroborated by other workers. ${ }^{15}$ This is particularly useful in field conditions where proper storage facilities may be lacking.

The Co-A test is simple to perform, practical and reproducible when the reagents are stored at $4^{\circ} \mathrm{C}$ for up to 4 months. The assay is not only sensitive and specific but also rapid; the result is obtained within $30-45 \mathrm{~min}$ of receipt of the sera. It requires no special technical expertise or expensive laboratory equipment or reagents and is, therefore, suitable for the detection of circulating serum antigen for the diagnosis of hydatid disease in field conditions or in less well equipped laboratories. This test is also useful for postsurgical follow-up cases by monitoring antigen levels in pre- and post-operative sera. It deserves further evaluation for possible wider application in the diagnosis and management of hydatid disease.

protein A-antibody mediated haemagglutination for serodiagnosis of hydatid disease. Med Sci Res 1987; 15: 1509-1510.

9. Parija SC, Mishra SR, Rao RS. Sensitised chick cells in the indirect haemagglutination test for echinococcosis. $J \mathrm{Med}$ Microbiol 1986; 22: 237-239.

10. Ali-Khan Z, Siboo R. Immune complexes in experimental alveolar hydatidosis. Tropenmed Parasitol 1983; 34 187-192.

11. Sogandares-Bernal F, Race MC, Dennis MV, Voge M Circulating antigens in infections of mice by tetrathyridia of Mesocestoides corti Hoeppli, 1925. Z Parasiten 1981; 64: $157-167$.

12. Leikana ES, Kovrova EA, Krasovskaya NN. Detection of circulating antigens in the blood stream of patients with hydatid disease, alveococcosis and trichinosis. Med Parazitol Parazit 1982; 60: 7-15. (In Russian).

13. Zvolinskene V. Determination of circulating hydatid antigens in the sera of patients with hydatidosis and their diagnostic significance. Acta Parasitol Litu 1983; 19: 56-62.

14. Craig PS, Bailey W, Nelson GS. A specific test for the identification of cyst fluid sample from suspected human hydatid infections. Trans $R$ Soc Trop Med Hyg 1986; 80 (2) : $256-257$

15. Koshi G, Thangavelu CP, Brahmadathan KN. The reliability and rapidity of coagglutination technic and its comparison with precipitin technics in the grouping of streptococci. $A m$ $J$ Clin Pathol 1979; 71: 709-712. 